histological and synaptophysin studies provide the optimal means of determining the temporal and spatial sequence of synaptogenesis in developing brain. sIR correlates with thalamocortical development and EEG maturation in the fetus and neonate. The four dominant patterns of fetal EEG are low voltage irregular 10-25 mcv at 5-10 cps; mixed activity $10-50 \mathrm{mcv}$ at $2.5-10 \mathrm{cps}$; high voltage slow $50-100 \mathrm{mcv}$ at $<5 \mathrm{cps}$, and trace alternant $20-100 / 5-25 \mathrm{mcv}$ at $2.5-10 / 2.5-15 \mathrm{cps}$. Surface abdominal EEG recordings were unsatisfactory. (Rosen MG et al, in Gluck L ed. Intrauterine asphyxia and the developing brain. Chicago, Year Book Med Publ, 1977).

\title{
POLYMICROGYRIA CLINICAL/IMAGING HETEROGENEITY
}

Researchers at the Royal Children's Hospital. Melbourne, Australia, and other international centers studied the imaging features of 328 patients with polymicrogyria referred from 6 centers, with detailed clinical data for 183 patients. Patterns of polymicrogyria defined by MRI were perisylvian $(61 \%)$, generalized (13\%), frontal (5\%), and parasagittal parieto-occipital (3\%); 15\% were unilateral. Periventricular grey matter heterotopia were associated in $11 \%$. Clinical sequelae included epileptic seizures $(76 \%)$, global developmental delay (70\%), spasticity $(51 \%)$, and microcephaly $(50 \%)$. The more extensive the pattern of polymicrogyria, the earlier the age of presentation and greater the severity of sequelae. Prevalence of epilepsy was similar in all polymicrogyria patterns, but generalized and bilateral forms had a lower age at seizure onset. Median age at presentation was 4 months; $38 \%$ presented in antenatal or neonatal periods. Males predominated with a gender ratio of 3:2. The findings should allow the definition of anatomoclinical syndromes of polymicrogyria and facilitate genetic counseling. (Leventer RJ, Jansen A, Pilz DT, et al. Clinical and imaging heterogeneity of polymicrogyria: a study of 328 patients. Brain May 2010;133:1415-1427). (Respond: Dr Richard J Leventer, Children's Neuroscience Centre, Royal Children's Hospital, Flemington Road, Parkville, Melbourne 3052, Australia; E-mail: richard.leventer@rch.org.au).

COMMENT. Polymicrogyria is an overfolding and abnormal lamination of the cortex, defined by MRI as cortical thickening and irregular cortical surface. It is a heterogeneous, frequently familial X-linked disorder of both genetic and environmental etiologies, resulting from abnormalities during late neuronal migration or early cortical organization. It is associated with chromosomal and duplication and deletion syndromes (eg 22q11.2 DiGeorge syndrome), congenital cytomegalovirus infection and ischemic insults. A pachygyria-polymicrogyria spectrum of cortical dysplasia in X-linked hydrocephalus is described in 3 boys with extensive cerebral malformations but normal laminar cortical neuronal architecture. (Graf WD, Born DE, Sarnat HB. Eur J Ped Surg 1998;8(Suppl 1):10-14). The prevalence of the perisylvian pattern of polymicrogyria suggests that the malformation occurs during the formation of cerebral fissures and sulci. Polymicrogyria is a highly epileptogenic disorder with $80 \%$ of patients presenting with seizures at an early age. 